\title{
VOLKMANN'S ISCHAEMIC CONTRACTURE BENEFITED BY MUSGLE SLIDE OPERATION
}

\section{Report of a Case}

\author{
N. W. Nisbet, Denedix, New Zealanid
}

A boy aged twelve years fell in 1949 and sustained a supracondylar fracture of the right elbow with backward displacement of the lower fragment. On the same day the fracture was reduced. The hospital notes are scanty, but it seems likely that there was some vascular damage at that time which escaped notice. Radiographs showed persistence of the backward displacement of the lower fragment, and ten days later an open reduction was carried out. This was followed by Volkmann's (1881) ischaemic contracture. Despite six months of corrective splintage a severe deformity developed. When examined early in 19:5n, the elbow

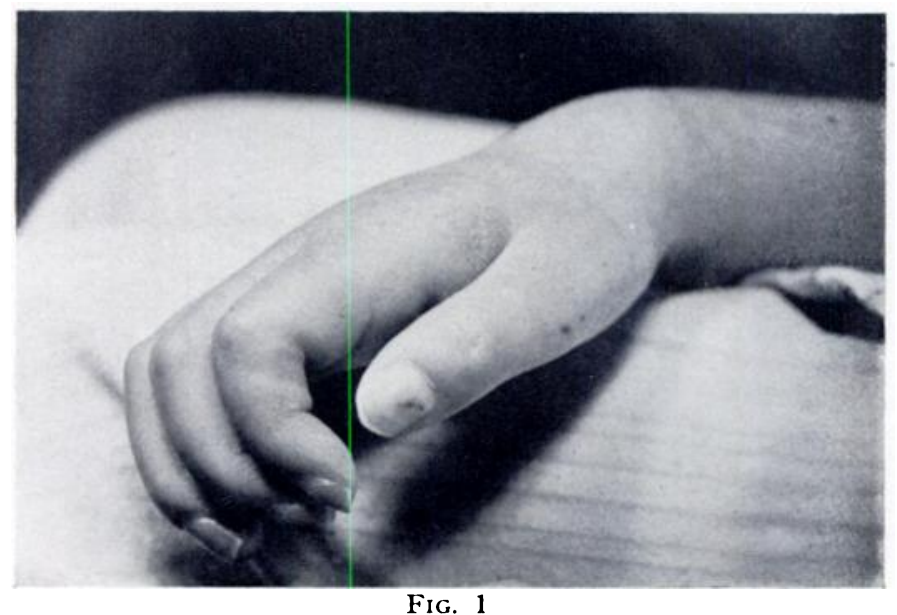

Before operation. Fingers shown in greatest extension.

movement was limited to 30 degrees, and there was severe flexion contracture of the fingers (Fig. 1). The radial pulse was absent. There was no loss of sensation in the fingers. An important finding was that there was an island of active muscle tissue in the common flexor group near the elbow. Because of the position of the wrist and fingers this muscle was not able to function, and the hand was almost useless.

Treatment - A muscle slide operation was undertaken. The technique described by Page (1933) was followed and will not be detailed here. Except for the mass of contractile muscle previously referred to, which was in the flexor digitorum profundus, the muscles of the flexor group were pale, fibrotic and matted together. The brachial artery was represented only by a small vessel. No correction was obtained until all the muscles had been stripped to the distal border of the flexor digitorum profundus and flexor pollicis longus in the lower part of the forearm. The linear attachment of the flexor digitorum sublimis was also stripped. When the attachments of the flexor muscles had been dissected free and stripped good correction was obtained (Fig. 2). Six months after operation a useful range of controlled movement of the fingers had been regained, and function was greatly improved (Figs. 2 to 4 ). There was at first a tendency to recurrent contracture, but with careful supervision, appropriate splinting and intensive re-education this has now passed off. The range of elbow movement has increased, probably because the pronator teres and the capsule were divided. 


\section{DISCUSSION}

The finding of an isolated piece of healthy muscle is of great interest. Clark (1946) and others have shown that mammalian muscle can regenerate rapidly after devascularisation, provided a piece of healthy muscle remains. Hughes (1948) produced histological evidence to suggest that regeneration can occur in man. Griffiths (1950) maintains that devascularised muscle may regenerate "years later." In our case the persisting healthy muscle may have escaped complete necrosis, or it may have regenerated from a few surviving fibres. There is no doubt, however, that regeneration has continued, especially with use, because since operation its power and bulk has increased greatly. It appears, therefore, that function was an

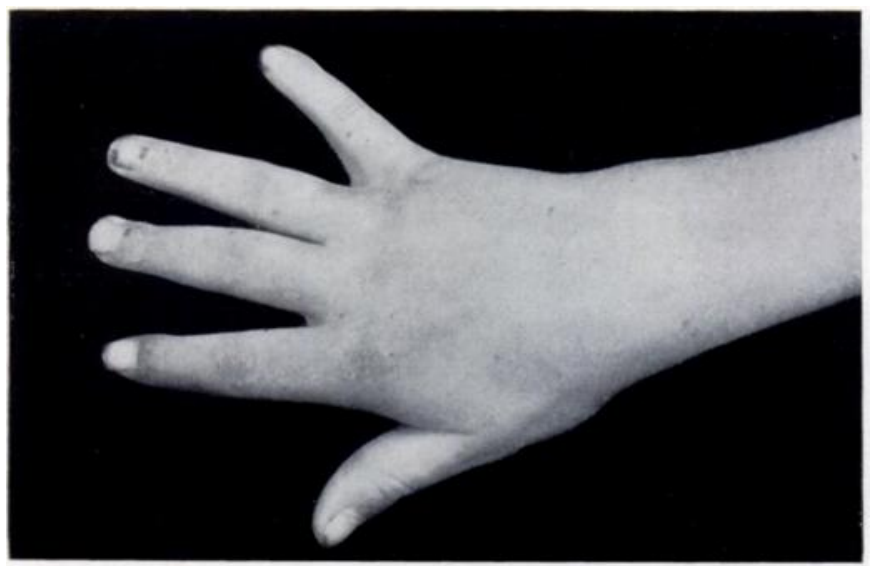

Fic. 2

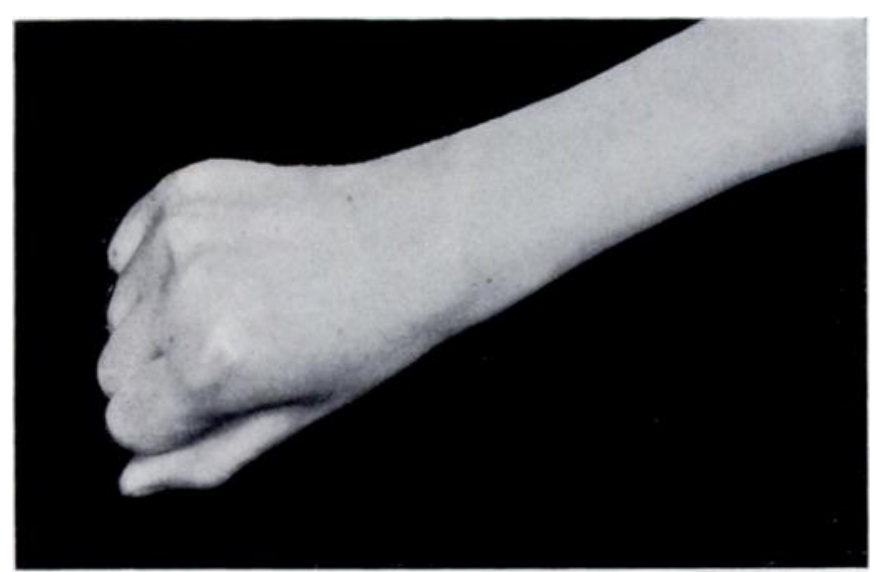

FIG. 3

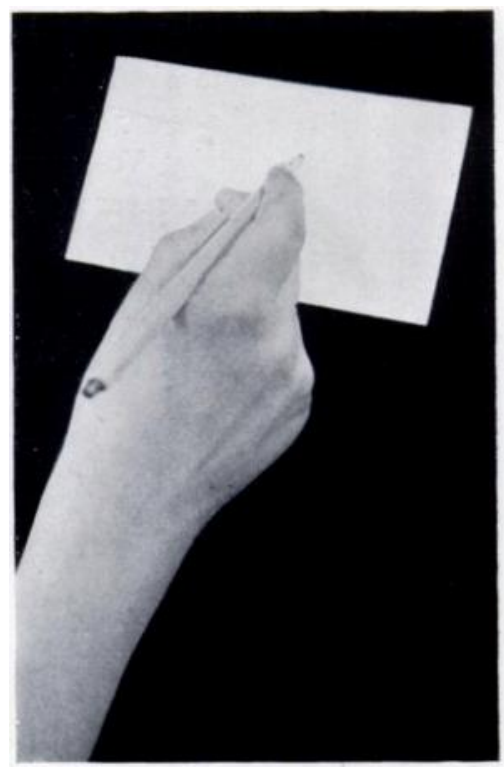

Fici. 4

After operation. Figures 2 and 3 show range of finger movement. Figure 4 exemplifies the satisfactory function obtained.

important stimulus and was prevented before operation by the severe contracture of the fingers. It is difficult to see how regeneration can occur years later, as Griffiths believes. All experimental work suggests that regeneration takes place rapidly and soon after devascularisation.

There is much to be learnt about vascular patterns within muscles (Clark 1946). ( ampbell and Pennefather (1919) showed the end-arterial supply of the gastrocnemius by an injection technique. A similar state of affairs seems to hold for the forearm flexors. I have injected the arterial supply of the flexor muscle group of a fresh cadavar with a plastic material, and dissolved off the tissues with hydrochloric acid. A single artery was found entering each flexor muscle belly, and there was little or no anastomosis between vessels of any size (Fig. i). 


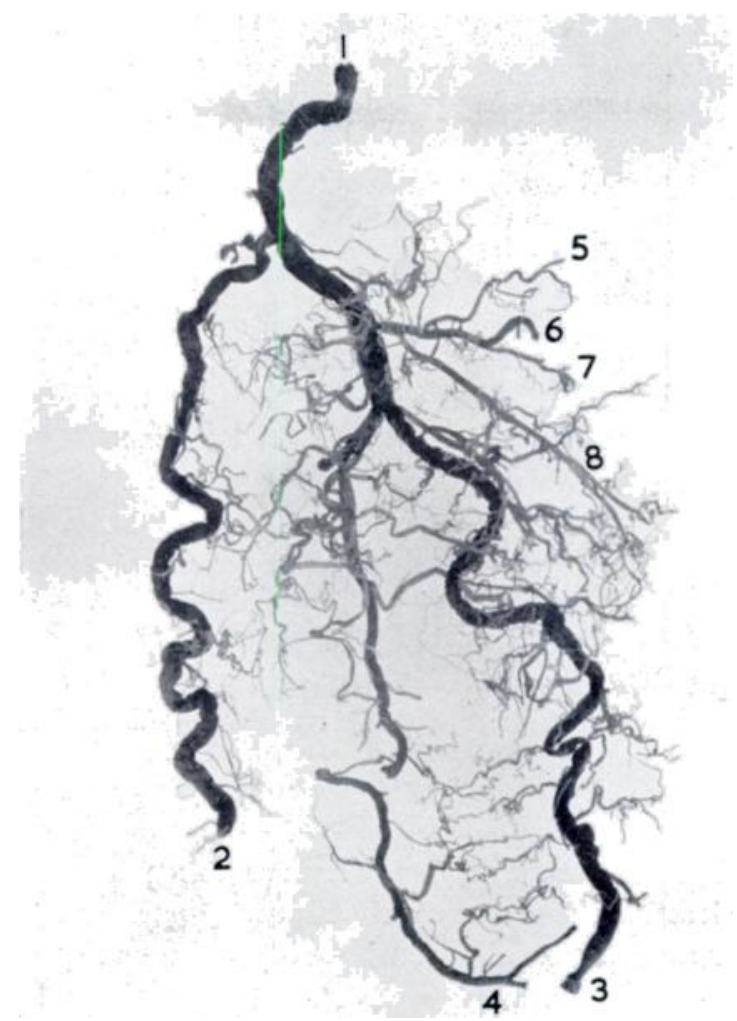

FIG. 5

Vascular tree of forearm and flexor muscles. 1) Brachial artery. 2) Radial artery. 3) Ulnar artery. 4) Posterior interosseous artery. 5, 6, 7 and 8) Muscular branches, each branch going into a single flexor muscle belly. Others have not been enumerated.

\section{SUMMARY}

1. A case of Volkmann's ischaemic contracture, in which function was greatly improved by a muscle slide operation, is described.

2. The possibility of regeneration of muscle after ischaemia is reviewed in the light of recent research.

3. Injection experiments suggest that the forearm flexors, like the gastrocnemius, are supplied by end arteries.

\section{REFERENCES}

Campbell, J., and Pexwefather, C. M. (1919): An Investigation into the Blood-Supply of Muscles. Lancet, i, 294.

CLARK, W. E. LE Gros (1946): Anatomical Problems Relative to the Traumatic Surgery of Muscle. Bulletin of War Medicine, 6, 267.

Griffiths, D. Ll. (1950): Certain Vascular Lesions. In Modern Trends in Orthopaedics, Chapter 13. Edited by Sir Harry Platt. London: Butterworth \& Co. (Publishers) Ltd.

Hughes, J. R. (1948): Ischaemic Necrosis of the Anterior Tibial Muscles Due to Fatigue. Journal of Bone and Joint Surgery, 30-B, 581.

PAGE, C. M. (1923) : Four Cases of Flexion Contracture of the Forearm Treated by a Muscle-sliding Operation. Proceedings of the Roval Society of Medicine (Section of Orthopaedics), 16, 43.

VolkmaNi, R. (1881): Die Ischaemischen Muskellähmungen und Kontrakturen. Zentralblatt für Chirurgie, $8,801$.

vOl. $34 \mathrm{~B}$, xo. 2 , MAY 1952 